\title{
Habitat selectivity of substrate-spawning fish: modelling requirements for the Eurasian perch Perca fluviatilis
}

\author{
Martin Snickars ${ }^{1, *}$, Göran Sundblad ${ }^{2,3}$, Alfred Sandström ${ }^{4}$, Lars Ljunggren ${ }^{2}$, \\ Ulf Bergström² ${ }^{2}$ Gustav Johansson ${ }^{5}$, Johanna Mattila ${ }^{1}$
}

${ }^{1}$ Husö Biological Station, Environmental and Marine Biology, Åbo Akademi University, BioCity, PO Box 123, 20521 Turku, Finland ${ }^{2}$ Swedish Board of Fisheries, Institute of Coastal Research, Box 109, 74071 Öregrund, Sweden

${ }^{3}$ Department of Limnology, Evolutionary Biology Centre (EBC), Uppsala University, Norbyvägen 18D, 75236 Uppsala, Sweden

${ }^{4}$ Swedish Board of Fisheries, Institute of Freshwater Research, Stångholmsvägen 2, 17893 Drottningholm, Sweden

${ }^{5}$ The Foundation for Uppland, Box 26074, 75026 Uppsala, Sweden

\begin{abstract}
Substrate spawning fish are believed to be selective in their choice of spawning habitat, yet few studies have shown the relative importance of different characteristics in terms of habitat quality. We used an extensive and detailed dataset to identify the factors that govern both large-scale $\left(10^{3}\right.$ to $\left.10^{5} \mathrm{~m}\right)$ and local-scale $\left(10^{1}\right.$ to $\left.10^{2} \mathrm{~m}\right)$ selection by a substrate-spawning fish, the Eurasian perch Perca fluviatilis L. Distribution of spawning habitat was strongly dependent on habitat characteristics defined by substrate, wave exposure, temperature and depth. The most important predictor was the type of spawning substrate, which generally consisted of different types of vegetation. Substrates providing rigidity and structural complexity were preferred, despite abundant presence of other substrate types. Shallow depth and sheltered areas were also selected habitat characteristics. The response to temperature was scale-dependent, with a stronger selection expressed at the local scale. The specific selectivity suggests that spawning patterns can be successfully modelled with sufficient detail using only a few fundamental environmental variables. Wave exposure and depth are readily available for large-scale spatial predictions, while temperature and substrate require further development in most coastal areas. The high specificity of the characteristics determining habitat quality suggests that it should be possible to apply this modelling approach for identification and conservation of spawning habitats of Eurasian perch and other substrate-spawning fishes in coastal waters.
\end{abstract}

KEY WORDS: Habitat modelling · Nursery areas $\cdot$ Large-scale maps · Macrophytes · Behaviour · Oviposition · Generalised additive model · GAM

\section{INTRODUCTION}

The distribution of organisms along gradients of environmental characteristics, reflecting their requirements in the habitat (Mitchell 2005), is a fundamental part of ecology. With advancements in computer power and statistical methodology, species distribution modelling has rapidly increased (e.g. Guisan \& Zimmerman 2000, Guisan \& Thuiller 2005). Environmental variables such as temperature, salinity, depth and vegetation have been used to predict the distribution of various organisms, e.g. macrophytes (Lehmann 1998) and spawning habitat for sole Solea solea (Eastwood et al. 2001). Analysing presence/absence patterns of species may be troublesome due to abundant absence observations, i.e. zero inflation caused by patchiness and aggregation patterns of mobile organisms, which make it difficult to assess specific habitat requirements and potentially result in a skewed availability of spatial predictions of mobile species compared to less mobile ones. However, data on less mobile life stages of mobile organisms may provide more accurate estimates of 
the relationship between distribution patterns and environmental conditions. Hence, due to an intimate connection between specific characteristics (defining the spawning habitat quality) and egg deposition, substrate-spawning fish species are hypothesised to be well suited for predictive modelling of habitat requirements.

Substrate-spawning fish species are common in all aquatic systems, and many of the apex species of commercial and recreational fisheries use specific substrates for spawning. As in many aquatic organisms, distribution and abundance of early life stages of fish are critical determinants of the population size (Houde 1989, Wahle \& Steneck 1991), but the characteristics and distribution of nursery areas, including spawning habitats, are usually poorly known. Research aiming at habitat mapping and identification of crucial habitat bottlenecks, such as critical environmental conditions constituting a spawning habitat of a species, is therefore essential for aquatic conservation (Halpern et al. 2005, Sale et al. 2005).

Our study species Eurasian perch Perca fluviatilis and its close North American relative, yellow perch $P$. flavescens, are widely distributed in fresh and brackish waters in the northern hemisphere. Both species are substrate spawners and attach a single gelatinous egg strand to substrates such as submerged vegetation or fallen tree branches (Thorpe 1977, Treasurer 1983, Urho 1996, Smith et al. 2001). Abiotic factors such as depth and temperature (Treasurer 1983, Gillet \& Dubois 1995, Karås 1996a) largely determine the spawning habitat. Spawning habitats for perch and several other warm-water fishes are often located in shallow water and sheltered areas, and where beneficial temperature conditions prevail during the spawning period (Karås 1996a, b, Sandström et al. 2005, Snickars et al. 2009). Thus far, attempts to model the preference of spawning habitats based on large-scale environmental conditions and on conditions expressed locally, such as the variability in substrate, depth and temperature, have not been reported. Yet, discrimination among spawning habitats occurs at local scales in marine and fresh substrate-spawning fish, since locally manifested habitat characteristics are important in heterogeneous waters (Huff et al. 2004, Gladstone 2007). Further, factors such as allelopathy from toxic metabolites, life-history strategy (perennial/annual) and morphological plasticity of vegetation species influence the distribution of many aquatic organisms (WiumAndersen et al. 1982, Kautsky 1988, Madsen et al. 2001), and may thus affect the availability of and suitability as a spawning substrate, thereby potentially influencing the habitat choice of fish.

The aim of this study was to use an extensive but detailed dataset to construct a statistically valid model containing those environmental factors that influence the selection of spawning habitat in a substratespawning fish at both large and local scales. A detailed approach was important, since many of the negative pressures are manifested locally, e.g. in decreased vegetation coverage (Eriksson et al. 2004), thus affecting the distribution of substrate-spawning fish. The results may be used in spatial predictive mapping of large areas. Modelling spawning habitat requirements would benefit the ongoing and increasingly needed efforts to map habitat requirements of sensitive life stages, and enable spatial assessments of escalating habitat degradation. Large-scale mapping of the distribution of recruitment habitats is inevitably important for efficient aquatic conservation in areas with strong human influence.

\section{MATERIALS AND METHODS}

Study area. The study area was located centrally in the Baltic Sea. The coasts of the Baltic Sea constitute one of the largest distribution areas of perch in the world, spanning $>1000 \mathrm{~km}$ from south to north and east to west. The area was chosen to be representative of and to include as many of the general environmental variables that govern the distribution of Baltic coastal fish species (e.g. Ådjers et al. 2006), and spawning perch in general (Treasurer 1983, Gillet \& Dubois 1995, Karås 1996a, Smith et al. 2001). The study area included the extensive archipelagos along the east coast of Sweden and the archipelago of Alland (Fig. 1). The area is non-tidal, with a near shore salinity normally ranging between 3 and 7 . The maximum summer water temperature ranges from 15 to $20^{\circ} \mathrm{C}$ in open water and between 20 and $25^{\circ} \mathrm{C}$ in sheltered shallow areas, and in winter the coastal waters are icecovered for around 3 mo.

Field survey. A field survey of spawning, i.e. visual observations of egg strands, was conducted at 22 study sites during the spawning season from April to June 2003. The sites were shallow and vegetated and were selected from a large pool of potential sites in order to increase the geographic distribution and generality of the findings (Fig. 1). Sites were randomly chosen in gradients of geomorphometry with respect to wave exposure in order to represent typical shallow habitats. The surface area of the sites ranged between 2 and 50 ha (mean $\pm \mathrm{SE}, 12.7 \pm 2.6 \mathrm{ha}$ ), with mean and maximum depth between 0.6 and $1.7 \mathrm{~m}$ and 1.5 and $3.6 \mathrm{~m}$, respectively (Table 1). The sites had soft bottoms with vegetation mainly consisting of submerged species such as Potamogeton spp., Chara spp. and Myriophyllum spicatum and the emergent Phragmites australis (Table 2). The composition of vegetation was surveyed 


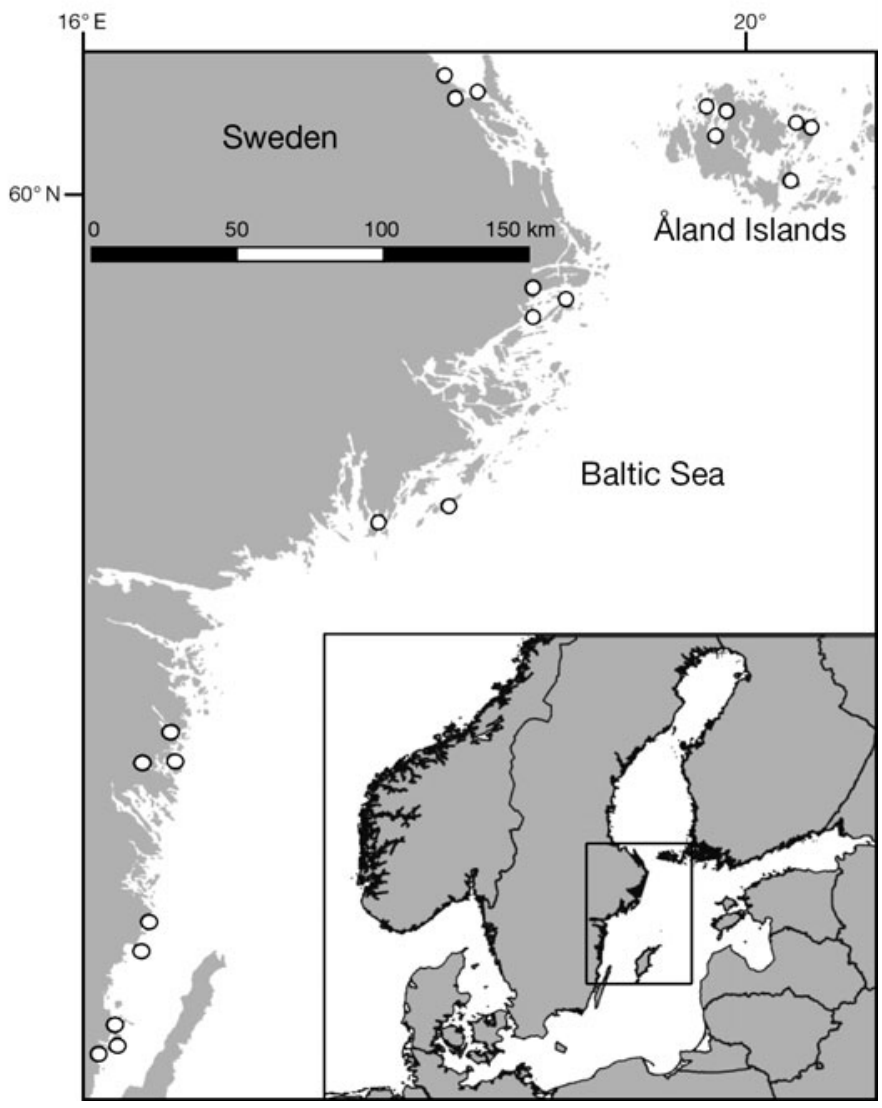

Fig. 1. Study sites along the Swedish and Åland coastline (white circles). Inset shows the study area in the Baltic Sea

twice at each site, and the egg strands were surveyed 3 to 4 times during the study period, with intervals of 14 to $20 \mathrm{~d}$. The fourth survey was excluded from analyses due to the low egg strand occurrence indicating that the end of the spawning season was exceeded. The survey of vegetation and perch egg strands was conducted by snorkelling along parallel transect lines (length from shore to shore: 20 to $480 \mathrm{~m}, 5$ to 12 lines site $^{-1}$ ), drawn perpendicular to the straight length axis that was measured from the opening to the end of each site. The first line was placed in the water at $5 \mathrm{~m}$ distance from the end of the site, the second line was placed parallel to and at $50 \mathrm{~m}$ distance from the first one, the third at $100 \mathrm{~m}$ distance from the second one and the following ones each at a $100 \mathrm{~m}$ distance from the previous one until reaching the opening, covering the entire site. Two additional lines were placed at $5 \mathrm{~m}$ distance from the $50 \mathrm{~m}$ long shorelines, thereby connecting the start and end points of the first and second line, respectively. For each egg strand encountered within $1 \mathrm{~m}$ on both sides of the transect line, substrate type on which the strand was attached and depth were noted. In order to contrast individual habitat choice of spawning females to availability at the site, the distribution of habitats was surveyed by placing a $50 \times 50 \mathrm{~cm}$ square at every $10 \mathrm{~m}$ of each transect line. At each square (32 to 291 squares site ${ }^{-1}$ ), the percentage cover of vegetation species (maximum 100\%) was assessed and water depth was noted (0.1 $\mathrm{m}$ accuracy). Temperature was measured at the start (littoral), the mid-point (open) and the end (littoral) of each transect line $20 \mathrm{~cm}$ above the sediment surface at every occasion and with automatic recorders every second hour at $1 \mathrm{~m}$ depth in the central part of each site during the study period. Salinity was measured once in the central part of each site during each survey. Salinity was not used in the modelling, as preliminary measurements in both littoral and open, deeper parts of the sites showed that the within-site variation was negligible. Since both the response variable and the predictor variables were monitored within the same area at a detailed scale, the modelling was conducted using the distribution of each individual egg strand as the response. By this approach, the species-environment relationship should accurately represent the realised distribution rather than the potential distribution when used in a predictive context (Lobo 2008).

Wave exposure. As a consequence of differences in geomorphometry and level of isolation, the sites varied with respect to wave exposure. Since wave exposure may have a fundamental effect on the composition of vegetation (Eriksson et al. 2004), sediment type (Isæus 2004) and hypothetically on egg strand deposition, wave exposure values $\left(\mathrm{m}^{2} \mathrm{~s}^{-1}\right)$ were estimated for each square with vegetation and egg strand noted along the transect lines. For all analyses, $\log _{10}$ values were used. Wave exposure was calculated using the

Table 1. Depth $(\mathrm{m})$, wave exposure $\left[\log _{10}\left(\mathrm{~m}^{2} \mathrm{~s}^{-1}\right)\right]$, temperature $\left({ }^{\circ} \mathrm{C}\right)$ in open $(\mathrm{O})$ and littoral $(\mathrm{L})$ parts of the study sites, and salinity. Values are mean \pm SE. Prevalence $(\%)$ is calculated as the percentage of squares with egg strands out of the total number of squares per visit at the 22 sites

\begin{tabular}{|c|c|c|c|c|c|c|}
\hline & Depth & Wave exposure & Temperature (O) & Temperature (L) & Salinity & Prevalence \\
\hline April to May & & & $9.3 \pm 0.4$ & $10.8 \pm 0.3$ & $4.7 \pm 0.2$ & 13.2 \\
\hline Mid-May & & & $14.1 \pm 0.3$ & $14.9 \pm 0.2$ & $5.0 \pm 0.1$ & 4.7 \\
\hline Early June & & & $15.8 \pm 0.3$ & $16.7 \pm 0.2$ & $5.1 \pm 0.2$ & 2.0 \\
\hline Mean & $1.4 \pm 0.1$ & $3.2 \pm 0.1$ & $13.8 \pm 0.3$ & $14.7 \pm 0.2$ & $4.9 \pm 0.1$ & 7.7 \\
\hline
\end{tabular}


Table 2. Frequency of occurrence (\%) of vegetation species and corresponding Eurasian perch Perca fluviatilis L. egg strands. The relative frequency of occurrence of egg strands is calculated as the number of observed egg strands divided by the sum of total number of egg strands and total number of squares with respective vegetation species. Also shown is the frequency of occurrence (\%) of egg strands per substrate class derived from dominating species percentage cover

\begin{tabular}{|c|c|c|}
\hline $\begin{array}{l}\text { Substrate class } \\
\text { Species }\end{array}$ & $\begin{array}{c}\text { Vegetation } \\
\text { Occurence (\%) }\end{array}$ & $\begin{array}{l}\text { Egg strands } \\
\text { Rel. occurence }\end{array}$ \\
\hline \multicolumn{3}{|l|}{ Emergent angiosperms } \\
\hline Phragmites australis & 5.6 & 43.4 \\
\hline $\begin{array}{l}\text { Schoenoplectus tabernae- } \\
\text { montani }\end{array}$ & 0.1 & 0 \\
\hline \multicolumn{3}{|l|}{ Submerged angiosperms } \\
\hline Myriophyllum spicatum & 4.6 & 3.7 \\
\hline Ruppia cirrhosa & 0.4 & 0 \\
\hline Ruppia maritime & 0.8 & 0 \\
\hline Potamogeton filiformis & 0.3 & 0 \\
\hline Potamogeton pectinatus & 13.7 & 33.6 \\
\hline Potamogeton perfoliatus & 0.5 & 0 \\
\hline Zannichellia palustris & 1.3 & 0 \\
\hline Ceratophyllum demersum & 2.3 & 0 \\
\hline Callitriche hermaphroditica & 0.2 & 0 \\
\hline Lemna trisulca & 0.1 & 0 \\
\hline Ranunculus circinatus & 0.1 & 0 \\
\hline \multicolumn{3}{|l|}{ Brown algae } \\
\hline Fucus vesiculosus & 6.2 & 11.9 \\
\hline Chorda filum & 0.7 & 0 \\
\hline \multicolumn{3}{|l|}{ Charophytes } \\
\hline Chara aspera & 1.9 & 0 \\
\hline Chara baltica & 1.3 & 0 \\
\hline Chara tomentosa & 7.9 & 3.3 \\
\hline Chara canescens & 0.1 & 0 \\
\hline Najas marina & 0.3 & 0 \\
\hline \multicolumn{3}{|c|}{ Green and yellow-green algae } \\
\hline Monostroma balticum & 0.2 & 0 \\
\hline Vaucheria spp. & 4.3 & 1.2 \\
\hline Non-vegetated & 49.2 & 2.9 \\
\hline Substrate class & Cover $(\%)$ & Occurence $(\%)$ \\
\hline Angiosperms & 18.3 & 18.8 \\
\hline Brown algae & 9.2 & 11.9 \\
\hline Charophytes & 12.6 & 2.4 \\
\hline Emergent angiosperms & 6.3 & 64.0 \\
\hline $\begin{array}{l}\text { Green and yellow-green } \\
\text { algae }\end{array}$ & 4.5 & 2.5 \\
\hline Non-vegetated & 49.2 & 0.5 \\
\hline
\end{tabular}

software WaveImpact (WI), which uses grids from a geographic information system (GIS). WI uses wind data, the distance from which waves potentially collect wind energy before reaching a specific point (fetch) and algorithms incorporating diffraction and refraction to create GIS grids with a resolution of $25 \mathrm{~m}$ (Isæus 2004).

Classification of vegetation. Vegetation was classified in order to assess general patterns of substrate preference. Classification was based on \% cover, and each square was classified as 1 of the following substrate classes: emergent angiosperms, submerged angiosperms, charophytes, brown algae or green/yellow-green algae. Squares were classified as non-vegetated if total coverage was $\leq 10 \%$. Frequency of occurrence of each recorded vegetation species, calculated as the number of squares with respective species divided by the total number of squares (including $0 \%$ cover squares), and class are listed in Table 2.

Modelling. Generalised additive models (GAMs) describing the relationship between egg strand presence/absence and environmental variables (substrate class, depth, wave exposure and temperature) were built with S-PLUS 6.0 statistical software (Insightful; Hastie \& Tibshirani 1990) using the GRASP package (Lehmann et al. 2002). We used a binomial error distribution and a logit link function in the model. A binomial model was used since the study was designed to model spawning habitats based on environmental variables measured at a scale of individual egg strands, i.e. substrate choice of female perch. Logistic models have been successfully used in habitat suitability studies (e.g. Stoner et al. 2001) and may even perform better than abundance models (Francis et al. 2005). Along each environmental variable, the smoother spline function ( $s$ in Eq. 1) was given 3 degrees of freedom and model selection was based on the Akaike information criterion (Akaike 1974). The probability of perch egg strand occurrence was modelled with an additive function:

Egg strand occurrence $=$ substrate $+s($ depth $)+s($ wave
exposure $)+s($ temperature $)$

Substrate was treated as a discrete factor in the model. In addition, separate models where each predictor variable was fitted independently, using the same settings as above, were constructed to assess potential variable contribution alone. Model performance was assessed with regards to overall goodnessof-fit $\left(\mathrm{D}^{2}\right)$ and by inspection of a receiver operating characteristic plot (ROC) as well as a 5-fold cross-validated ROC (cvROC, Fielding \& Bell 1997), which results in a good balance between model stability and performance (Maggini et al. 2006). ROC plots assess the overall discriminatory ability of a model by assessing sensitivity and their equivalent values $(1-$ specificity) for all possible threshold values, resulting in an overall score that can range between 0.5 and 1 (Fielding \& Bell 1997, where values $>0.9$ can be considered as a very good discriminatory ability (Maggini et al. 2006). All models were additionally checked for correlated variables (collinearity) using Pearson's r. Mean values of water temperature and salinity were compared among sites with the non-parametric MannWhitney $U$-test. 


\section{RESULTS}

In total, 244 perch egg strands were registered in the 3151 squares (2907 vegetation survey +244 egg strands) used in the model (7.7\% prevalence). Spawning was most intense during the first visit in late Aprilearly May when $68 \%$ of the total number of egg strands were registered with $13.2 \%$ prevalence (Table 1). Egg strands were observed at 15 of the 22 sites. Salinity ranged between 3.5 and 5.7 at the sites during the study period, and there was no difference between the sites with (mean $\pm \mathrm{SE}, 4.9 \pm 0.2)$ and without $(5.1 \pm 0.2)$ egg strands (Mann-Whitney $U: Z=-0.67, \mathrm{p}=0.50$ ).

\section{Modelling}

The model had an overall goodness of fit $\left(\mathrm{D}^{2}\right)$ of 0.39 with a null deviance of 1717 and residual deviance of 1048. Total and residual degrees of freedom were 3151 and 3136, respectively. Model performance based on ROC scores indicated high model fit $(\mathrm{ROC}=0.91)$ and stability based on 5-fold cross validation (cvROC = 0.91, Fielding \& Bell 1997, Maggini et al. 2006). Correlation coefficients between predictor variables in the model were low, with the largest value between temperature and wave exposure $(\mathrm{r}=-0.31)$.

Overall, substrate was the most important variable for the distribution of perch egg strands (Table 3). Substrate explained 3 to 5 times more variation than the other variables when building separate models for each variable. The difference in contribution within the final model was smaller than the separate models. Substrate was the most influential variable and represented $32 \%$ of the total explained deviance followed by wave exposure $(31 \%)$, temperature $(20 \%)$ and depth $(18 \%)$.

Partial response curves were used to study the relationship between spawning substrate selection and the 4 variables, as well as between categories of substrate. The substrate with the strongest positive effect was emergent angiosperms, mainly consisting of shoots of Phragmites australis from the previous year (Fig. 2, Table 2). Submerged angiosperms (11 species, dominated by Potagometon pectinatus and Myriophyllum sp.) were also actively chosen as spawning substrate, as was Fucus vesiculosus in the substrate class brown algae. Chara tomentosa, the second most common vegetation species after $P$. pectinatus, was underrepresented as spawning substrate (Table 2), but no avoidance was apparent in the partial responses (Fig. 2). Similarly, the rare Vaucheria spp. had a neutral effect in the GAM model. Non-vegetated areas with $\leq 10 \%$ total vegetation cover dominated as potential substrate in the survey, but were clearly avoided, and only 7 egg strands were found on non-vegetated substrate.
Perch preferred sheltered sites for spawning. The positive effect from low wave exposure levelled out around $3\left[\log _{10}\left(\mathrm{~m}^{2} \mathrm{~s}^{-1}\right)\right]$ and there was a negative effect at estimates over $3.5\left[\log _{10}\left(\mathrm{~m}^{2} \mathrm{~s}^{-1}\right)\right]$. Wave exposure ranged between 2.44 and $4.59\left[\log _{10}\left(\mathrm{~m}^{2} \mathrm{~s}^{-1}\right)\right]$. Values up to 3 characterise extremely sheltered areas, and values between 3 and $3.5\left[\log _{10}\left(\mathrm{~m}^{2} \mathrm{~s}^{-1}\right)\right]$ are mainly found in sheltered archipelago areas with a large amount of land and islands. Small basins and semi-enclosed larger bays in the inner and middle archipelago regions normally range between 3.5 and $4.5\left[\log _{10}\left(\mathrm{~m}^{2} \mathrm{~s}^{-1}\right)\right]$, while the outer archipelago with only a few small islands can reach up to $5\left[\log _{10}\left(\mathrm{~m}^{2} \mathrm{~s}^{-1}\right)\right]$.

For depth, egg strand occurrence had an optimum at $0.9 \mathrm{~m}$, with a negative selection of deeper and shallower waters (Fig. 2). The deepest areas were clearly avoided, and only 3 egg strands were observed deeper than $2.5 \mathrm{~m}$.

The response to temperature showed a similar pattern as depth, i.e. a slightly skewed bell shaped envelope with a positive effect on egg strand presence between 7 and $12^{\circ} \mathrm{C}$, and the lowest temperature where egg strands were observed was $7.6^{\circ} \mathrm{C}$. At higher temperatures, there was a rapid decrease in egg strand presence. Differences in temperature regarding egg strand presence were noted at the 2 spatial scales, within and between sites, respectively. The mean water temperature registered by the automatic recorders between 7 May and 20 June was marginally higher, $15.0 \pm$ $0.4^{\circ} \mathrm{C}$ (mean $\pm \mathrm{SE}, \mathrm{N}=15$ ) at sites with egg strands, compared to $14.1 \pm 1.3^{\circ} \mathrm{C}(\mathrm{N}=7$, Mann-Whitney $U: Z=$ $-0.48, \mathrm{p}>0.05$ ) at sites with no egg strands. Within sites, mean water temperature above the sediment surface was higher in the littoral $\left(14.7 \pm 0.2^{\circ} \mathrm{C}\right)$ than in the central parts of the sites $\left(13.8 \pm 0.3^{\circ} \mathrm{C}\right.$; Mann-Whitney $U: Z=-2.72, \mathrm{p}=0.006)$.

\section{DISCUSSION}

We present a widely applicable model of easily measured and commonly used abiotic factors that explain spawning habitat selection of a common substratespawning fish. Temperature, depth (Eastwood et al.

Table 3. Model contribution of each environmental variable expressed as the percentage of explained deviance in the model and alone

\begin{tabular}{|lrr|}
\hline Factor & In model & Alone \\
\hline Substrate & 12.3 & 25.5 \\
Depth & 6.9 & 5.1 \\
Wave exposure & 11.9 & 4.8 \\
Temperature & 7.8 & 7.5 \\
\hline
\end{tabular}



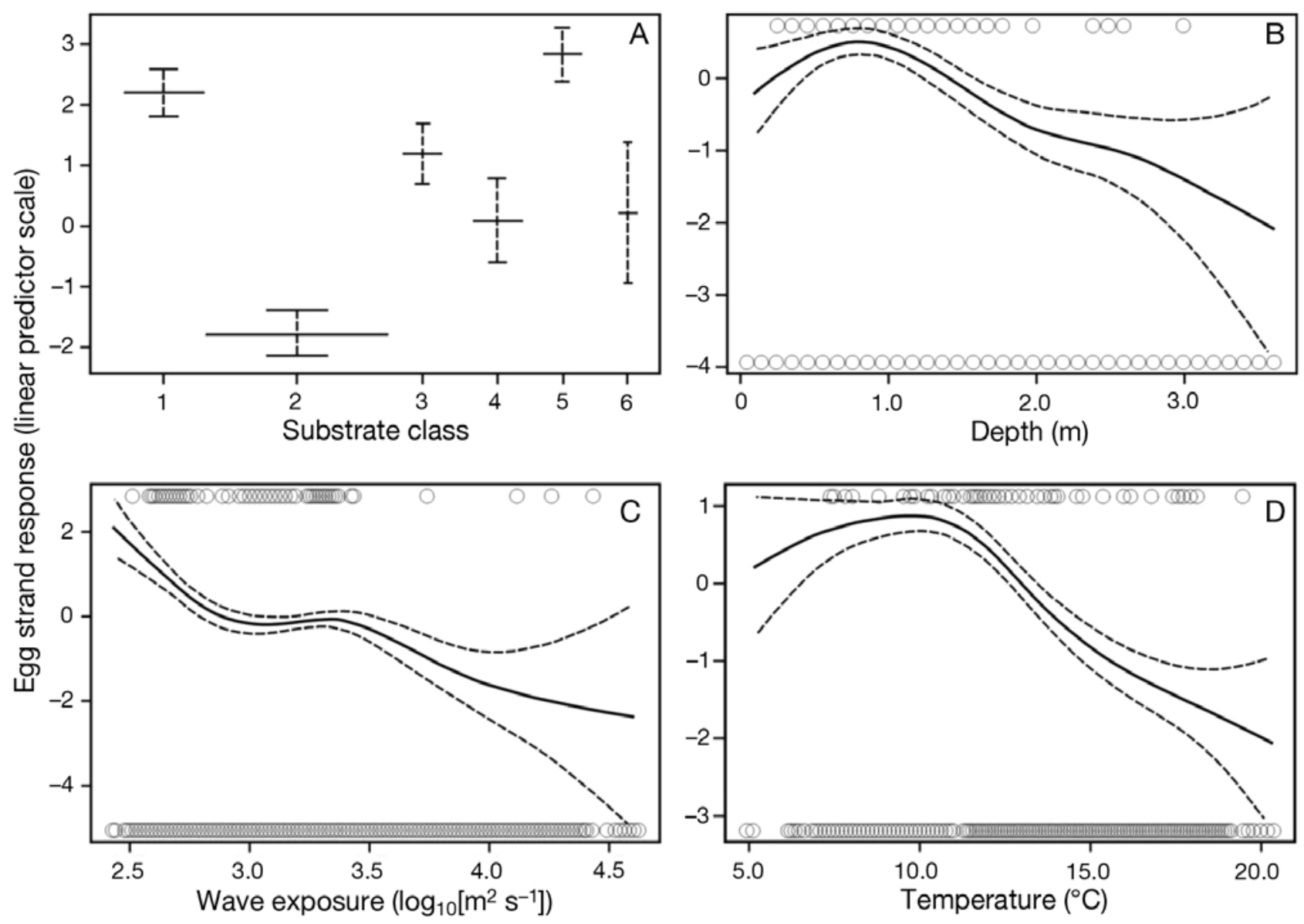

Fig. 2. Perca fluviatilis. Eurasian perch egg strand response for the 4 environmental variables, where a value $>0(<0)$ indicates a positive (negative) selection. Response with respect to (A) categorical substrate classes (1: submerged angiosperms; 2: nonvegetated; 3: brown algae; 4: charophytes; 5: emergent angiosperms; 6: green and yellow-green algae). The width of the horizontal line indicates the relative sample size. Response expressed in the scale of the linear predictor (B) depth, (C) wave exposure and (D) temperature. Circles in (B-D) indicate observed presence (top) and absence (bottom) of egg strands along the continuous predictors. Dashed line indicates $\pm 2 \mathrm{SE}$

2001, Huff et al. 2004), wave exposure and vegetation composition are important factors controlling the abundance of early life stages of many species, including perch (e.g. Karås 1996a, b, Snickars et al. 2009). The geographical position of the study area in the central Baltic Sea further adds to the potential for extrapolating results to other coastal areas with comparable conditions. Our results indicate that predictions using a few fundamental environmental descriptors are also possible in situations where habitat selection is expressed at different scales. The study underlines the importance of using extensive and detailed datasets in predicting species-environment relationships in heterogeneous environments (Jackson \& Harvey 1989) where the habitat selectivity is expressed locally (Huff et al. 2004, Gladstone 2007). These findings contrast with studies from homogeneous environments such as vegetated littorals of (small) lakes, where spawning fish may be less selective and spawn randomly under beneficial or uniform conditions (Treasurer 1983, Urho 1996). Hence, the spawning behaviour of perch and other substrate-spawning fish species may vary with the heterogeneity of the environment and be more complex than previously reported (but see Smith et al. 2001).

At the large scale, perch tended to select the warmer sites, but there was a high variation and overlap in the temperature between sites with and without egg strands. Temperature is a large-scale factor that controls juvenile fish assemblages in similar environments (Snickars et al. 2009), and it is likely that a larger number of study sites would have resulted in a clearer large-scale difference in temperature. However, the results suggest that temperature has a pronounced effect at the local scale, as perch selected the warmer littoral zone regardless of the mean temperature of the 
sites. The egg strand response curve indicated an optimum temperature similar to other studies at the same latitudes (Thorpe 1977, Sandström et al. 1997), signifying that temperature is a direct proximal gradient that influences spawning (Karås 1996b, Sandström et al. 1997) and embryonic development (Treasurer 1983, Saat \& Veersalu 1996). Mortality of perch larvae increases at temperatures below $10^{\circ} \mathrm{C}$ (Saat \& Veersalu 1996), and the behaviour of perch in the present study suggest that the adults actively select warm water in order to benefit survival of offspring.

The relative preference of the different spawning substrates varied, indicating a highly selective behaviour. Selective spawning behaviour is known to occur in fish species in heterogeneous coastal waters (e.g. Gladstone 2007) and in lotic waters (Baxter \& Hauer 2000), where the local conditions in streams may vary at the scale of only metres. Less than half of the vegetation species were used as spawning substrate. These had the common characteristic of being large and structurally complex species, which likely is an important quality in supporting the attached egg strands. This feature was most evident for the emergent Phragmites australis from the previous year that, while being uncommon, was a preferred substrate. At latitudes where ice and storms during winter often displace and destroy littoral vegetation, vegetation species with a robust structure and a thick root system that is firmly attached to the sediment may withstand and remain in place and overwinter, thus constituting a potential spawning substrate in the following spawning season. This may be an important feature of habitat quality in many littoral aquatic systems in the northern hemisphere. Accordingly, $P$. australis was the dominant species at depths $<0.5 \mathrm{~m}$, while Fucus vesiculosus was the preferred substrate in deeper waters. The lifehistory strategy of vegetation species may play a role, since spawning starts in early spring before annual vegetation has emerged and therefore the structural substrate provided by perennial species may be the available spawning habitat. Only few egg strands were found on Chara tomentosa, although this was the second most abundant vegetation species and possesses a structural rigidity similar to the preferred substrates. This is an indication that the substrate was less preferred or avoided despite the suggested neutral effect shown in the model. A potential explanation for this is that Chara spp. have negative allelopathic effects on the growth of many aquatic organisms (Wium-Andersen et al. 1982). Thus, a plausible explanation could be that perch avoid vegetation that produces toxic exudates because the egg strands are in direct contact with the substrate for a long period of time, potentially affecting the development of the eggs. Similarly, our results indicated that perch avoided the other potentially harmful substrate type, i.e. areas that were non-vegetated. Smith et al. (2001) demonstrated a high mortality of perch egg strands laid on non-vegetated substrate, potentially due to less oxygenated water, and concluded that spawning substrate selection may increase fitness due to the varying effects of different substrates on the survival of early life stages. The avoidance of non-vegetated areas and potentially allelopathic substrates suggests that both physical and chemical cues may affect the spawning habitat selection.

Perch clearly selected shallow waters, with an optimum spawning depth between 0.5 and $1 \mathrm{~m}$, which agrees with earlier reports from lakes (Treasurer 1983). However, there are large differences in published spawning depths of perch from lakes, ranging from $0.2 \mathrm{~m}$ (Smith et al. 2001) to between 4 and $12 \mathrm{~m}$ (Gillet \& Dubois 1995). The large discrepancies between studies are not surprising, since depth can be considered an indirect variable. Instead, other variables may have more direct mechanistic effects on spawning habitat choice. For example, yellow perch optimum spawning depth in small lakes has been shown to be a trade-off between temperature and negative effects of high solar radiation on the eggs (Huff et al. 2004). This study indicated a negative effect in extremely shallow waters, less than $0.5 \mathrm{~m}$, which could be an effect of risk of drought, destruction from wave-breaking or solar radiation. The negative effect of waters deeper than $2 \mathrm{~m}$ described in this study has also been shown for egg densities in a lake at the same latitude (Viljanen \& Holopainen 1982), probably due to temperatures being too low for successful perch spawning in deeper waters (Karås 1996a) and due to a lack of preferable spawning substrates.

There was a clear preference for low wave exposure. Even though this study did not investigate the mechanisms by which wave exposure acts on spawning habitat distribution, it may have a negative effect by directly harming and removing the egg strand from its substrate or indirectly by increasing water exchange leading to slower increase of temperature in spring, thus delaying hatching and decreasing survival. Another example of the interrelation among variables that can affect the distribution of spawning habitats is the change in composition of submerged vegetation (Eriksson et al. 2004) and the decrease in plant height as an effect of high wave exposure (Kautsky 1988, Madsen et al. 2001), with potential consequences for substrate-spawning species dependent on rigid structures for egg deposition.

Although no strong correlation was found between the predictor variables in this study, the differences in significance found when the models were fitted alone or when combining variables indicate some degree of 
interrelation among the fitted predictors, and point to some differences in their attributes. The stronger effect of substrate when fitted alone likely reflects the unconditional attribute of the variable, i.e. that non-vegetated areas may be harmful as spawning substrate regardless of other environmental conditions. On the other hand, the stronger effect of wave exposure when combining variables both reflects the length of this gradient and the interrelationship with other gradients that are common in heterogeneous coastal areas. Larger-scale studies have shown how combining environmental gradients, including wave exposure, defines different habitat types and juvenile fish communities (Snickars et al. 2009). It is likely that the lack of strong correlations between the predictors in the present study can be attributed to a shorter range covered by some of the studied gradients. Although the modelled, sensitive early life stage motivates a restricted length of some of the gradients, the largescale negative correlation found between water temperature and wave exposure (Snickars et al. 2009) should add to the potential of using wave exposure as a predictor when mapping habitat characteristics (e.g. Sundblad et al. 2009).

The spawning behaviour of Eurasian perch suggests that substrate-spawning fishes may be selective in their choice of spawning habitat. There is a high potential for predictive habitat modelling of this species, as well as other coastal species with similar habitat preferences, using only a few environmental variables. The most important predictors of the spawning habitat selection were type of vegetation and wave exposure, followed by temperature and depth. The study thus stresses the current lack of accurate spatial data in many coastal areas. Detailed maps of submerged vegetation and temperature with sufficient spatial extent are currently the largest limitations for predictive modelling of shallow waters. These variables may be mapped by remote sensing, GIS modelling techniques or by the development of suitable proxy variables. Maps of wave exposure and depth are readily available for high-resolution, large-scale predictions. These 2 variables together represented about half of the variation explained in the model, suggesting that predictive modelling of perch spawning habitat may be performed to cover the immediate need for fish habitat maps in e.g. marine spatial planning. It is likely that many other substrate-spawning fishes, just like Eurasian perch, have highly specific spawning habitat requirements. The accelerating habitat degradation in aquatic systems, especially in coastal areas, emphasises the need for habitat mapping and conservation actions for fishes dependent on shallow coastal areas for reproduction. Our study lays the groundwork for comparative studies on the importance of common abi- otic factors for predicting nursery habitats of perch and other substrate-spawning species (Sundblad et al. 2009).

Acknowledgements. We thank the staff of the Husö Biological Station and the crew of RV 'Sunbeam' for excellent working conditions and A. Alm, K. Rosqvist, J. Hansen, J. Lycken, J. Persson, M. Pienimäki and M. Scheinin for help with fieldwork. The study was funded by the EU Interreg IIIA project Juvenile Fish Production in Shallow Bays, and by the Interreg IIIB project BALANCE.

\section{LITERATURE CITED}

Ådjers K, Appelberg M, Eschbaum R, Lappalainen A, Minde A, Repečka R, Thoresson G (2006) Trends in coastal fish stocks of the Baltic Sea. Boreal Environ Res 11:13-25

Akaike H (1974) A new look at the statistical model identification. IEEE Trans Automat Control 19:716-723

Baxter CV, Hauer FR (2000) Geomorphology, hyporheic exchange, and selection of spawning habitat by bull trout (Salvelinus confluentus). Can J Fish Aquat Sci 57: 1470-1481

Eastwood PD, Meaden GJ, Grioche A (2001) Modelling spatial variations in spawning habitat suitability for the sole Solea solea using regression quantiles and GIS procedures. Mar Ecol Prog Ser 224:251-266

Eriksson BK, Sandström A, Isæus M, Schreiber H, Karås P (2004) Effects of boating activities on aquatic vegetation in the Stockholm archipelago, Baltic Sea. Estuar Coast Shelf Sci 61:339-349

> Fielding AH, Bell JF (1997) A review of methods for the assessment of prediction errors in conservation presence/ absence models. Environ Conserv 24:38-49

Francis MP, Morrison MA, Leathwick J, Walsh C, Middleton C (2005) Predictive models of small fish presence and abundance in northern New Zealand harbours. Estuar Coast Shelf Sci 64:419-435

Gillet C, Dubois JP (1995) A survey of the spawning of perch (Perca fluviatilis), pike (Esox lucius), and roach (Rutilus rutilus), using artificial spawning substrates in lakes. Hydrobiologia 300-301:409-415

Gladstone W (2007) Selection of a spawning aggregation site by Chromis hypsilepis (Pisces: Pomacentridae): habitat structure, transport potential, and food availability. Mar Ecol Prog Ser 351:235-247

Guisan A, Thuiller W (2005) Predicting species distribution: offering more than simple habitat models. Ecol Lett 8: 993-1009

Guisan A, Zimmerman NE (2000) Predictive habitat distribution models in ecology. Ecol Model 135:147-186

- Halpern BS, Gaines SD, Warner RR (2005) Habitat size, recruitment, and longevity as factors limiting size in stagestructured species. Am Nat 165:82-94

Hastie TJ, Tibshirani RJ (1990) Generalized additive models. Chapman \& Hall, New York

Houde ED (1989) Subtleties and episodes in the early life of fishes. J Fish Biol 35:29-38

Huff DD, Grad G, Williamson CE (2004) Environmental constraints on spawning depth of yellow perch: the roles of low temperature and high solar ultraviolet radiation. Trans Am Fish Soc 133:718-726

Isæus M (2004) Factors structuring Fucus communities at open and complex coastlines in the Baltic Sea. PhD thesis, Stockholm University 
Jackson DA, Harvey HH (1989) Biogeographic associations in fish assemblages: local vs. regional processes. Ecology 70: 1472-1485

Karås P (1996a) Basic abiotic conditions for production of perch (Perca fluviatilis L) young-of-the-year in the Gulf of Bothnia. Ann Zool Fenn 33:371-381

Karås P (1996b) Recruitment of perch (Perca fluviatilis L) from Baltic coastal waters. Arch Hydrobiol 138:99-121

Kautsky L (1988) Life strategies of aquatic soft bottom macrophytes. Oikos 53:126-135

Lehmann A (1998) GIS modeling of submerged macrophyte distribution using generalized additive models. Plant Ecol 139:113-124

Lehmann A, Overton MJ, Leathwick J (2002) GRASP: generalized regression analysis and spatial prediction. Ecol Model 157:189-207

Lobo JM (2008) More complex distribution models or more representative data? Biodivers Inf 5:14-19

Madsen JD, Chambers PA, James WF, Koch EW, Westlake DF (2001) The interaction between water movement, sediment dynamics and submersed macrophytes. Hydrobiologia 444:71-84

Maggini R, Lehmann A, Zimmerman NE, Guisan A (2006) Improving generalized regression analysis for the spatial prediction of forest communities. J Biogeogr 33: 1729-1749

Mitchell SC (2005) How useful is the concept of habitat? - a critique. Oikos 110:634-636

Saat T, Veersalu A (1996) The rate of early development in perch Perca fluviatilis L and ruffe Gymnocephalus cernuus (L) at different temperatures. Ann Zool Fenn 33:693-698

Sale PF, Cowen RK, Danilowicz BS, Jones GP and others (2005) Critical science gaps impede use of no-take fishery reserves. Trends Ecol Evol 20:74-80

Sandström O, Abrahamsson I, Andersson J, Vetemaa M (1997) Temperature effects on spawning and egg development in Eurasian perch. J Fish Biol 51:1015-1024

Editorial responsibility: Konstantinos Stergiou, Thessaloniki, Greece
Sandström A, Eriksson BK, Karås P, Isæus M, Schreiber H (2005) Boating and navigation activities influence the recruitment of fish in a Baltic Sea archipelago area. Ambio 34:125-130

Smith C, Douglas A, Jurajda P (2001) Oviposition site selection and embryo mortality in perch. J Fish Biol 58:880-882

Snickars M, Sandström A, Lappalainen A, Mattila J, Rosqvist K, Urho L (2009) Fish assemblages in coastal lagoons in land-uplift succession: the relative importance of local and regional environmental gradients. Estuar Coast Shelf Sci 81:247-256

Stoner AW, Manderson JP, Pessutti JP (2001) Spatially explicit analysis of estuarine habitat for juvenile winter flounder: combining generalized additive models and geographic information systems. Mar Ecol Prog Ser 213:253-271

Sundblad G, Härmä M, Lappalainen A, Urho L, Bergström U (2009) Transferability of predictive fish distribution models in two coastal systems. Estuar Coast Shelf Sci 83:90-96

Thorpe J (1977) Synopsis of biological data on the perch Perca fluviatilis Linnaeus, 1758 and Perca flavescens Mitchill, 1814. FAO, Rome

- Treasurer JW (1983) Estimates of egg and viable embryo in a lacustrine perch, Perca fluviatilis. Environ Biol Fishes 8: 3-16

Urho L (1996) Habitat shift of perch larvae as survival strategy. Ann Zool Fenn 33:329-340

Viljanen M, Holopainen IJ (1982) Population density of perch (Perca fluviatilis L) at egg, larval and adult stages in the dys-oligotrophic Lake Suomunjärvi, Finland. Ann Zool Fenn 19:39-46

Wahle RA, Steneck RS (1991) Recruitment habitats and nursery grounds of the American lobster Homarus americanus: A demographic bottleneck? Mar Ecol Prog Ser 69: 231-243

> Wium-Andersen S, Anthoni U, Christophersen C, Houen G (1982) Allelopathic effects on phytoplankton by substances isolated from aquatic macrophytes (Charales). Oikos 39:187-190

Submitted: February 25, 2009; Accepted: September 9, 2009 Proofs received from author(s): December 14, 2009 